\title{
Optimal Frequency stability Control Strategy for a Grid-Connected Wind/PV/FC/BESS Coordinated with Hydroelectric Power Plant Storage Energy System Using Variable Structure Control
}

\author{
Adel Elgammal and Curtis Boodoo
}

\section{ABSTRACT}

Because of the growing nonlinear and complexity nature of microgrid systems for example battery energy storage systems, wind-turbine fuel cell, photovoltaic, and micro hydro power plants (BESSs/FC/WT/PV/ Micro Hydro), load-frequency management has been a difficulty. The development of a load-frequency controller based on ProportionalIntegral-Derivative (PID) for an autonomous microgrid (MG) with hydro, wind, and PV RES is shown in this article. The suggested LFC goal is to retain the frequency of the micro hydro power plant under variable load situations by controlling the sharing of output power constant generator between the dummy loads and consumer. Using an adaptive fuzzy logic controller to govern nearly the generating unit's whole operation, the suggested control technique optimally chooses PID settings for each load value. The suggested fuzzy logic-based controller regulates the plant's frequency output despite fluctuating user loads and manages energy distribution by separating the micro network into separate departures connected in priority order. The suggested frequency controller uses a centralised LFC approach centred on a combination of smart load and Battery Energy Storage System to manage the MG frequency (BESS). It regulates MG frequency by providing active power balancing for a variety of events that such systems face in real-world settings, such as energy surplus generation and energy shortage. In Simulink/MATLAB, the suggested structure is simulated. The simulation results clearly demonstrate the proposed frequency controller's ability to dump extra power when the customer load varies while maintaining a consistent supply frequency.

Keywords: Load frequency controller, micro hydropower plant, microgrid, multi-area interconnected power systems, photovoltaic generation, renewable energy sources, self-tuning fuzzy control.

\author{
Published Online: September 13, 2021 \\ ISSN: 2736-5506 \\ DOI : $10.24018 /$ ejenergy.2021.1.4.17 \\ Adel Elgammal* \\ The University of Trinidad and Tobago \\ UTT, Utilities Engineering, Point Lisas \\ Campus, Trinidad and Tobago. \\ (e-mail: adel.elgammal@utt.edu.tt) \\ Curtis Boodoo \\ The University of Trinidad and Tobago \\ UTT, Utilities Engineering, Point Lisas \\ Campus, Trinidad and Tobago. \\ (e-mail: curtis.boodoo@utt.edu.tt)
}

*Corresponding Author

\section{INTRODUCTION}

Because of the growing need for energy, electrical energy generation is critical. In addition to large-scale hydropower facilities, small-scale hydropower plants are built to meet the need. Hydroelectric power plants play an important part in the production of electricity. Small hydroelectric energy is a type of RES. In most parts of the world, small hydropower offers a lot of promise [1]. On a small scale, micro-hydro power plants harness energy from falling water, such as plunging mountainous rivers, generating typically $5-100 \mathrm{~kW}$ using a run off river kind of flowing water and do not require the installation of costly dams. The working of the micro-hydro power plant resembles that of big hydroelectric plant in concept. Micro-hydro power plant generating systems are viewed as an appealing method of electrical power generation for rural settlements with no access to an electrical grid. As a result, it is considered as the most cost-effective and sustainable source of electricity for rural communities' offgrid regions [2]. It also has the advantage of being accessible
7 days a week, 24 hours a day, unlike other RES like wind and sun. Furthermore, unlike major hydro plants, it does not necessitate the installation and maintenance of dams. Consumers require uninterrupted electricity at the rated voltage and frequency in an electric energy structure. By controlling the generator's excitation, the voltage is kept within set limits [3]. In most situations, an Automatic Voltage Regulator is used to do this (AVR). By eliminating the imbalance between power used and power created, the frequency of power supply is controlled. The electrical power output $(\mathrm{Pe})$ and mechanical power input $(\mathrm{Pm})$ of the generator must balance for proper and effective frequency regulation. When the turbine mechanical power input exceeds the electrical load linked to the generator, the generator accelerates and the frequency rises. Likewise, the inverse is true. Due to the fluctuating power demands of consumers, the load in actual power systems changes frequently and unpredictably, resulting in an imbalance between the power consumed and the power generated. As a result of this activity, the frequency varies, necessitating frequency control 
[4]. Under isolated mode, the LFC's job is to regulate the producing electric power in reaction to frequency variations while staying below allowed limits. The objective of the LFC in grid-connected mode is to manage net power interchanges in tie line to set levels in addition to maintaining the constant frequency [5]. As a result, regardless of the operating mode, controller design is critical to solving the load frequency controller problem in micro hydro power plant [6]. A number of control approaches for the load frequency controller issue have been described in the literature, including adaptive control [11], [12], hybrid intelligent control [8], fuzzy multimodel control [7], neural-network-based integral control [10], multiple flow control [9] to mention a few. A review [13] looked into contemporary views concerning distribution network management and control for small/micro hydro power facilities. SMC is the most appealing of the control techniques offered because of its invariance characteristic [14]-[16]. There has recently been a surge in interest in using control technologies [17], [18]. The frequency management problem of a remote small hydropower plant was solved by means of a fuzzy sliding-mode governor [19]. Two types of SMC governors for hydropower plants were explored in [20][24] has further reports. The majority of the articles listed make the premise that all state variables of hydroelectric plants are quantifiable. Because just a fraction of states are quantifiable, the LFC design for micro hydro power structures should have as few state variables as feasible. PID tuning has been approached in a variety of ways. PID controller tuning, on the other hand, is not an easy task, particularly when the plants to be managed are unstable and nonlinear. The use of an improved genetic algorithm dubbed the Global Ranking Genetic Algorithm to tune PID controller settings has been proposed [25]. The findings demonstrate that the suggested approach is capable of tuning PID controllers to perfection. Using two interactive tools, we demonstrate the construction of a Fractional Order PID controller in this article [26]. The first tool allows users to construct Fractional Order PID controllers in the time and frequency domains and study the outcomes of altering userselected parameters. The second device, which employs a loop shaping approach, permits the user to automatically conclude the controller settings. These approaches can enhance PID controller responsiveness, but they also make PID a time-consuming and more complex procedure. Intelligent control approaches, such as fuzzy logic control, may be a viable solution to these issues due to their resilience. [27] Describes a centralized approach that uses a basic multiple-area power station to carry out these optimization procedures throughout the whole model. The simplification, however, is centered on the incorrect assumption that all of power structure's subsystems are comparable, which is not the case. The simulation model in the article differs considerably from the actual structure due to this assumption. Another difficulty with centralized approaches is that, even if they work properly on the low-order test structure, they will run into exponentially more computational issues as the system rises in scale. The large-scale energy infrastructure may be decentralized into smaller subsystems by considering tie-line signals as disruptions, because tie-line interfaces result in weakly linked terms across regions. Decentralized power systems have been subjected to a variety of control approaches. Decentralized PI or PID controllers are described in [28]-[32]. In [33]-[36], the controller was utilized to solve the decentralized Load Frequency control difficulties. H2/H $\infty$ control is renowned for its resistance to parameter uncertainty. Other decentralized solutions to the LFC problem include ramp following control, predictive control scheme, optimum tracking method, and disturbance accommodation control which may be found in [37]-[40]. Rather than just true or false, the FLC technique is centered on the fuzzy logic variables and fuzzy set theory can have any value between 0 and 1 . The choice will be determined using particular fuzzy logic functions when the variables have been chosen. In this article, the results of employing the FLC approach to the decentralized Load Frequency control problems are presented in [41]-[44]. [41] describes a FLC built straight from a power structure's fuzzy model. For a tworegion multiple unit power structure, [42] introduces a FLC centered tie line bias management approach. [43] presents an analogous technique for mutual cycle power plant. A comparison between FLC and standard PID control approaches is included. The conventional PI controller and the fuzzy gain scheduled PI controller were also evaluated in [44]. One of the highest widely used computer intelligence algorithms is the genetic algorithm (GA). It has been shown to be successful in solving a complicated optimization issue [45] involving PI controllers adjusted using linear matrix inequalities and GA on decentralized three area nine-unit power structure. The PI controller based on GALMI is found to be considerably easier to design than the $\mathrm{H} 2 / \mathrm{H} \infty$ controllers in [45], despite the fact that the both approaches function similarly. In [46]-[56], numerous researches have been done to suggest various FLC architectures optimized by various soft computing approaches. Hybrid particle swarm optimization [46],[47] methods have recently been used to optimize scaling factors of fuzzy PI controller output and/or input. Some researchers have proposed hybrid PSO-levy flight algorithm [48], hybrid local unimodal sampling [49], [50], hybrid harmony search-cuckoo optimization algorithm [51], mine blast algorithm [52], hybrid improved firefly algorithm [53], and hybrid differential evolution-PSO [54] as optimization methods for tuning output/input SFs of FPID controllers for various kinds of power systems. In [55], a fuzzy gain planned PID controller for a hybrid PV battery structure is presented. [56] Proposes an Instrumentation, Control and Automation adjusted FPIDN double-I controller. To obtain a fuzzy PI derivative with filter (FPIDN) controller, a first order filter is utilized in the derivative block of a fuzzy proportional integral derivative controller. The noise signal at the higher frequency disturbs its derivative. Few scientists have suggested FPIDN controllers with output/input SFs determined using consumption [50] and ICA [56] methods in the literature. As shown in [58], [59], it is also possible to combine fuzzy with artificial neural systems to achieve superior outcomes.

Because of the changing structure, unpredictable load demands, nonlinearities, parameter ambiguity, and constantly increasing scale and complexity of linked power structure, automatic production controller is regarded as the most critical challenges. As a result, an experienced, intelligent, and resilient control structure is required for the linked power system's steady functioning and the delivery of energy during 
abrupt load demand disruptions. This study presents a unique fuzzy-proportional integral derivative controller as an expert control method for dealing with automated generation control and optimizing controller settings. A self-tuning controller fuzzy logic-based was proposed to handle parameter uncertainties of standard controllers, for example microgrid modelling uncertainty, alteration in microgrid's operating point, and operation conditions. In addition, with the effect of renewable resources, a mixed fractional-order and fuzzy logic controller is employed for LFC management of an off-grid microgrid. The fractional-order controller's construction is versatile, and its performance is reliable. A unique metaheuristic whale method was utilized to best calculate the output and input scale coefficients of fractional orders and FLC of the fractional order controller so as to get a better functioning for the suggested controller. A microgrid comprising a wind turbine, micro hydro power plant, solar systems, and energy storage devices is used to demonstrate the proposed method. The comparison of the suggested controller's results with those of the classic Proportional Integral Derivative controller demonstrates that the optimized self-tuning fuzzy controller outperforms the classic PID controller in terms of frequency deviation reduction, speed of response, and operation characteristics against load deviations.

\section{HYBRID WIND/PV/FC/BESS COORDINATED WITH Hydroelectric Power Plant Power System CONFIGURATION}

The capacity to maintain a steady frequency after a large imbalance or interruption between production and load is critical since the microgrid can be disconnected from the main network and operate in an islanded mode. Nondispatchable resources, for example solar and wind producers, on the other hand, generate a slew of issues, including increased frequency variation and voltage deviation. Additionally, variations in consumer load utilization have an impact on stability, necessitating frequency and voltage regulation in microgrids. When a result, the microgrid will vary regularly as the load changes and the microgrid sources fail to provide the load requirement on time. It will be difficult to regulate frequency since not all renewable units engage in LFC and primary control, thus renewable power units may be required to produce power as well as contribute in primary and secondary frequency control. Via regulating for the loss in production, diesel generators may effectively reduce frequency variations. In a microgrid, load-frequency regulation is critical in this regard. The diesel generator can adjust for power fluctuations via control loop in load-frequency control. The traditional Variable Structure controller creates a closed-loop control to compensate for power oscillation produced by frequency variations. In the article, several systems for LFC in microgrids that are mostly independent of the grid have been suggested. Fig. 1 depicts the proposed framework for loadfrequency management in this research. Micro hydro power plants, Wind turbine generators, Photovoltaic panels, fuel cells, and energy storing devices such as the BESS make up the framework of the islanded AC microgrid network (BESS). The following is the demand-supply equation:

$$
P_{\text {Load }}+P_{M H}+P_{P V}+P_{W T} \pm P_{B E S S} \pm P_{F C}=0
$$

Because PVs and WTGs are affected by the environment, the secondary controller can be implemented by means of a Micro Hydro and FC tools. The frequency modulation variations in MG sources are shown in the diagram below:

$$
\Delta P_{\text {Load }}+\Delta P_{M H}+\Delta P_{P V}+\Delta P_{W T}+\Delta P_{B E S S}+\Delta P_{F C}=0
$$

Integral control improves the system's reaction time while eliminating steady state inaccuracy for a step input. The proportionate gain, on the other hand, is inversely proportional to the peak overshoot, which is extremely undesirable. Increased proportional gain improves the system's transient responsiveness. In the lack of integral gain, the system shows steady-state inaccuracy. As a PI controller, combining both integral and proportional gains with the control rule provides the following compromise:

$$
u(t)=K_{P} \Delta e+K_{I} \int \Delta e d t
$$

It was discovered that utilizing PI control as a compromise approach does not remove the contradiction between dynamic and static accuracy. The use of a variable structure controller might address this problem. For traditional load frequency management, the control law of a variable structure controller is as follows:

$$
u(t)= \begin{cases}K_{P} \Delta e & \Delta e>\varepsilon \\ K_{I} \int \Delta e d t & \Delta e<\varepsilon\end{cases}
$$

where $\mathrm{KI}$ and KP are controller's integral and proportional gain constants, respectively, and $>0$ is a constant. In terms of controller gains, the cases in this study require special attention. According to the findings of the research, generation control is influenced by load disturbance and system loading. The ON/OFF control valve may start functioning with continuous control by dump load after the peak variation in frequency has been decreased to zero in some situations. It creates a steady state error, which is produced by a consistent and continuous increase or decrease in generation that lasts as long as the ON/OFF control valve is engaged. As a result, the Voltage Source Converter law for traditional power structures must be changed. The suggested Voltage Source Converter logic is described as follows:

$$
u(t)= \begin{cases}K_{P 1} \Delta e+K_{I 1} \int \Delta e d t & \Delta e>\varepsilon \\ K_{P 2} \Delta e+K_{I 2} \int \Delta e d t & \Delta e<\varepsilon\end{cases}
$$




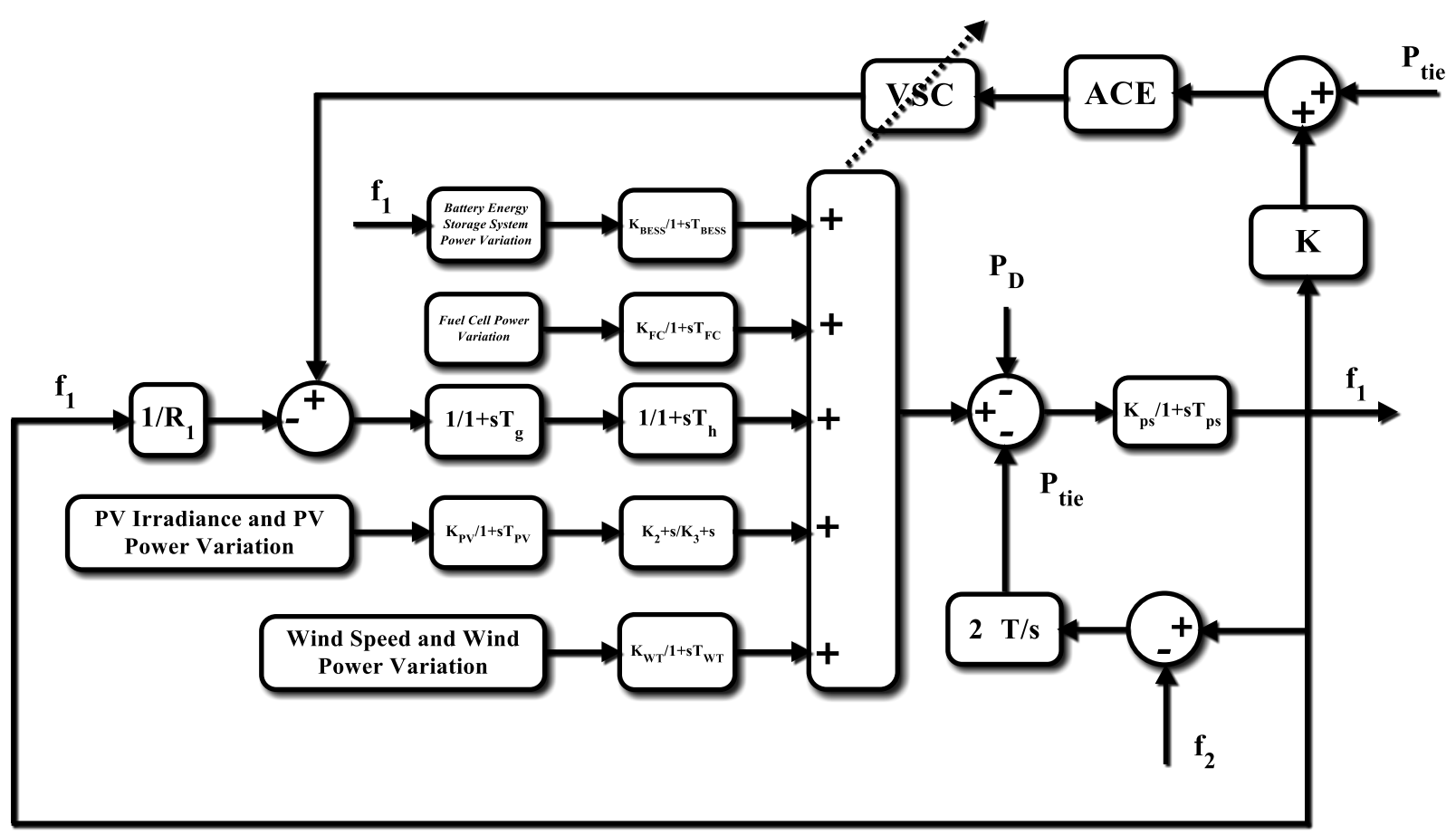

Fig. 1. Block diagram of the planned microgrid's frequency domain.

Fig. 2 depicts the recommended variable structure controller method as a block diagram. Variable Structure controllers need adjusting and agreeing on values of four factors, known as the Variable Structure controller's gains or coefficients, in order to design and implement them. Tuning these coefficients, on the other hand, is not easy, and various methods and procedures have been offered to solve the problem. Offline or Online techniques, which regulate the values of the Variable Structure controller parameters at any given moment, are one of these ways for building a Variable Structure controller. Self-tuning or Adaptive Variable Structure controllers and Multi-objective Variable Structure controllers with fuzzy decision making are two further Variable Structure-based control techniques. Using fuzzy logic decision making to design and tune Variable Structure controller coefficients is similar to adaptive controllers in that it is based on human knowledge. It also relies on the ability to infer fuzzy systems that provide a one-of-a-kind deal for Variable Structure control coefficient values at any given time. A fuzzy approach analyses the values of the Variable Structure controller coefficients accurately and inserts them in the control system after receiving an error and error derivative at any time. The fuzzy self-tuning controller's overall schematic is illustrated in Fig. 3 and Fig. 4 shows a fuzzy control structure with three outputs and two inputs. As control inputs, frequency changes and derivatives of frequency changes were employed. The K1 and K2 coefficients are responsible for placing the input signals inside the permitted range and expanding or compressing the fuzzy input range. Input scaling coefficients are the names given to these coefficients. The outputs of this system are also the values of the integral coefficients, three derivative and proportional. The output scaling coefficient, or Ko, is a scaling coefficient that functions as a link between the fuzzy controller's output and the system's input. The governor system receives the control signal generated by the fuzzy selftuning controllers as an auxiliary signal.

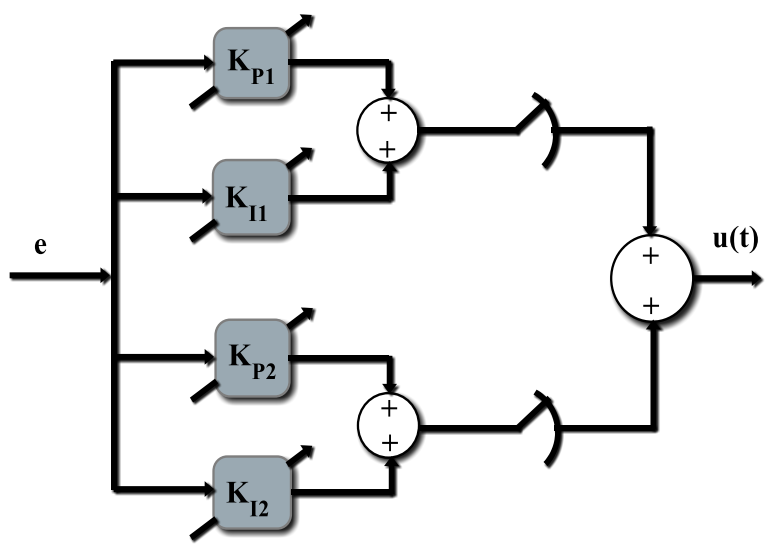

Fig. 2. Optimal tuned Variable Structure Control.

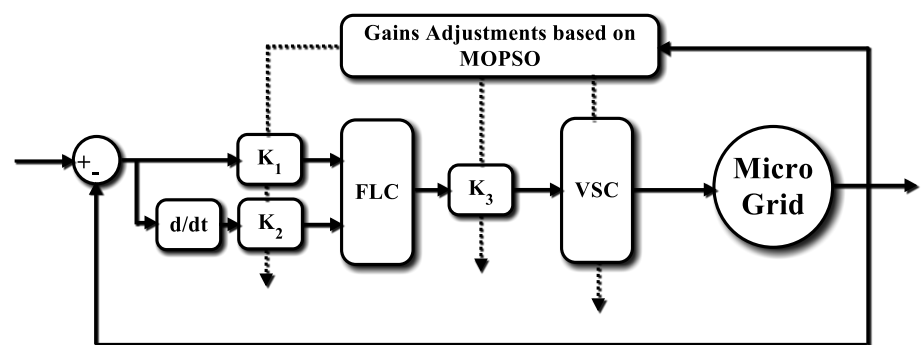

Fig. 3. The suggested fuzzy self-tuning controller's structure.

\section{Simulation Results AND Discussions}

The major goal of this research is to conclude the best LFC controller improvements for minimizing system frequency deviation fast. The MOPSO method was used to solve this problem by minimizing the stated objective function with the appropriate specifications and restrictions. A cost function is created based on the expected supplies and restrictions to optimize the controller's settings. The ITAE, IAE, ITSE, and ISE are some of the most often utilized cost functions in engineering (integral-time-multiplied-AE). The ISE, on the other hand, is the most often used cost function because it is 
simple to compute and allows for the separation of overdamped and underdamped systems. To eliminate negative error components, the ISE squares the error. Larger mistakes are penalized more than minor ones. It has quick reactions and allows for minor oscillations as time passes. The result shows that as compared to other approaches, ISEbased tuning requires less iteration for global convergence. As a result, ISE is used as $\mathrm{J}$ in this work due of its excellent recital. the following functions have been considered as an objective function and the controller parameters bounds as the constraint is expressed as the following:

$$
\begin{aligned}
& J_{1}=\int_{0}^{t}\left(\Delta f_{1}^{2}+\Delta f_{2}^{2}+\Delta P_{\text {tie } 12}^{2}\right) d t \\
& J_{2}=\int_{0}^{t} t\left(\Delta f_{1}^{2}+\Delta f_{2}^{2}+\Delta P_{\text {tiel } 2}^{2}\right) d t \\
& J_{3}=\int_{0}^{t}\left(\left|\Delta f_{1}\right|+\left|\Delta f_{2}\right|+\left|\Delta P_{\text {tie } 12}\right|\right) d t \\
& J_{4}=\int_{0}^{t} t\left(\left|\Delta f_{1}\right|+\left|\Delta f_{2}\right|+\left|\Delta P_{\text {tiel2 } 2}\right|\right) d t
\end{aligned}
$$

where, $\Delta$ Ptie is power incremental change in tie line, and $\Delta \mathrm{fl}$ and $\Delta \mathrm{f} 2$ are system frequency deviations. To improve the fuzzy self-tuning controller's efficiency in this work, the MOPSO is used to calculate the fractional-order parameters, as well as output and input coefficients of the controller. The frequency variation in the duration 0 to $t$ is represented by $\Delta f$ in the preceding optimization equation. The findings of the suggested method for LFC of the microgrid are presented in this section. The optimization program's maximum number of iterations and the technique's maximum number of particles are set to 100 and 50, respectively. Frequency control for changes in system characteristics, frequency control for variable load step changes, and frequency control for load step changes were examined using simulation findings. Step variations in load are calculated using a $20 \%$ change in the load. Results show the MOPSO's optimization outcomes in this case. In addition, Fig. 4 shows simulation results for LFC for step variations of $20 \%$ in the load. Fig. 5 depicts the power production of the micro hydro power plant, fuel cell, solar panels, and wind turbines. Centered on the observed findings, it can be concluded that the suggested method's frequency response for LFC management is better, quicker, and has less oscillations than previous approaches. Step load variations are introduced to the microgrid to show the resilience of the suggested controller against varied load changes at different periods. Fig. 6 displays the simulation results of microgrid's frequency response with varied load variations. In addition, Fig. 7 depicts the power production of RES. The recommended controller, as illustrated in Fig. 7, has decreased frequency deviations caused by varied load variations. It features a faster reaction time and more dampening than prior controllers while having lower amplitude.

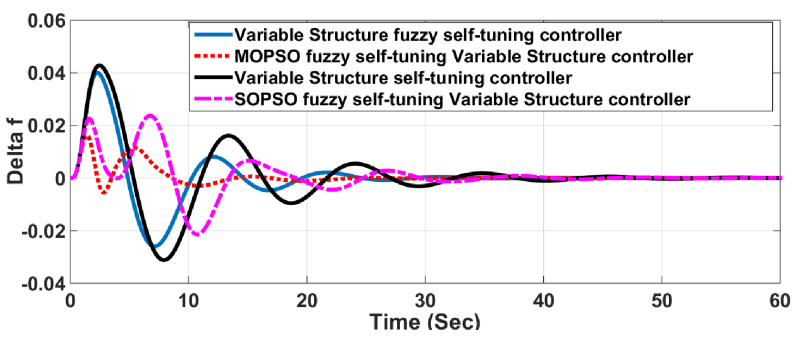

Fig. 4. The frequency response of the microgrid obtained for different control methods.

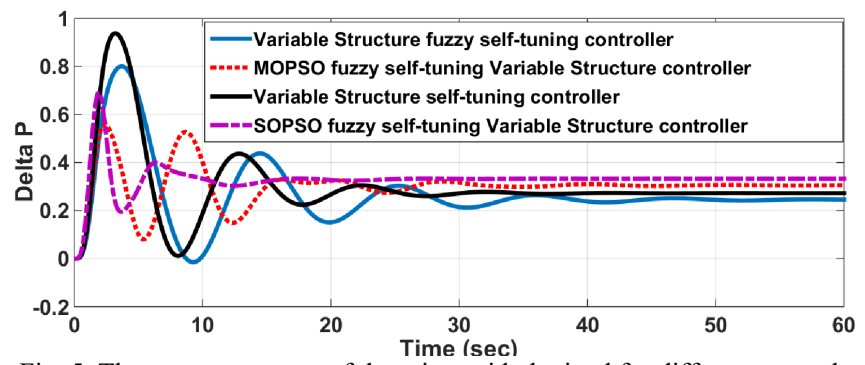

Fig. 5. The power response of the microgrid obtained for different control methods.

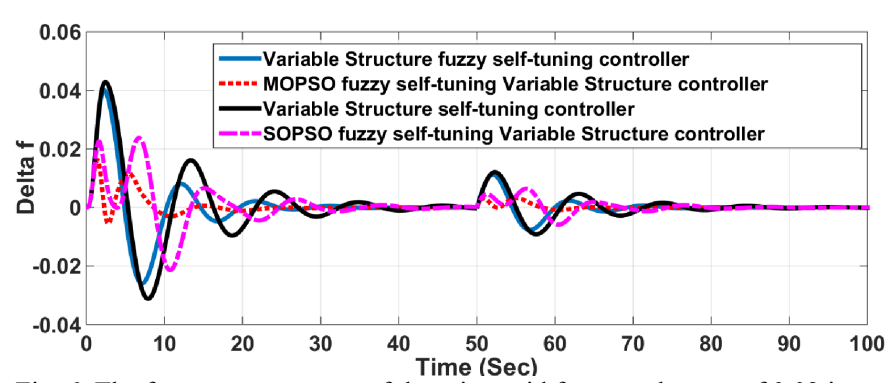

Fig. 6. The frequency response of the microgrid for step changes of 0.02 in the load obtained for different control methods.

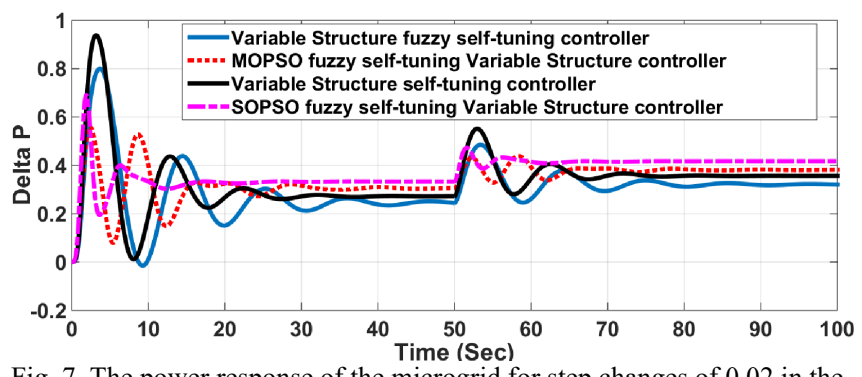

Fig. 7. The power response of the microgrid for step changes of 0.02 in the load obtained for different control methods.

\section{CONCLUSION}

In this analysis, a novel LFC management technique for a microgrid structure including Battery energy storage systems, fuel cell, wind-turbine, photovoltaic, and Micro hydro power plant is utilized to overcome the conventional PID controller`s constant parameters. In this technique, the fuzzy self-tuning controller can assist the uncertainties induced by operating system points, changing operating circumstances, parametric changes, and as well as system modelling and improve the control system's performance, along with reducing proportional integral derivative issues. The fuzzy self-tuning control in this approach adds various parameters to the system for LFC depending on the conditions. A MOPSO method was also utilized to rise the performance of the suggested controller. The fuzzy self-tuning controller's 
output is identical to the proportional integral derivative control coefficients, but they fluctuate dynamically in various conditions.. A microgrid including hydro power, energy storage devices, fuel cells, solar systems, and wind turbines is used to test the suggested control technique. The simulation results demonstrate that the suggested fuzzy self-tuning fractional-order controller for LFC management of microgrids, optimized with the whale approach, has a high efficiency and performance. The suggested strategy's main advantage is its resistance to huge load demands and its superiority over a variety of new clever classical/fuzzy controllers. The control approach outperforms a variety of strategies in terms of over/under shoots, oscillations, settling time, and other performance index values. Finally, so as to justify the controller's robustness, a robustness analysis is carried out. Finally, a robustness research is carried out to express the suggested controller's performance and strength with a $20 \%$ deviation in all micro grid parameters, as well as random power load demands in diverse locations. The suggested controller is shown to be robust and stable under nominal conditions, with broad variations in system parameters, load patterns, superior responses with lower peak deviations, and shorter settling times.

\section{REFERENCES}

[1] I. Sami, N. Ullah, S. M. Muyeen, K. Techato, M. S. Chowdhury and J. -S. Ro, "Control Methods for Standalone and Grid Connected MicroHydro Power Plants with Synthetic Inertia Frequency Support: A Comprehensive Review," in IEEE Access, vol. 8, pp. 176313-176329, 2020, doi: 10.1109/ACCESS.2020.3026492.

[2] M. E. M. Ali, A. M. Kassem and H. F. A. Hamed, "Modeling and Control of a Mini Hybrid Hydro Matrix / Wind in Micro Grid Applications," in IEEE Access, vol. 8, pp. 170843-170852, 2020, doi: 10.1109/ACCESS.2020.3022753.

[3] S. V. Kamble and S. M. Akolkar, "Load frequency control of micro hydro power plant using fuzzy logic controller," 2017 IEEE International Conference on Power, Control, Signals and Instrumentation Engineering (ICPCSI), 2017, pp. 1783-1787, doi: 10.1109/ICPCSI.2017.8392021.

[4] K. Shahzad, A. R. Khan, M. S. Khalid and A. Qamar, "Voltage and Frequency Control of PV, Micro-hydro and Biomass Based Islanded Microgrid," 2018 Clemson University Power Systems Conference (PSC), 2018, pp. 1-6, doi: 10.1109/PSC.2018.8664029.

[5] A.A. Zamani, E. Bijami, F. Sheikholeslam, B. Jafrasteh, "Optimal fuzzy load frequency controller with simultaneous auto-tuned membership functions and fuzzy control rules," Turkish Journal of Electrical Engineering \& Computer Sciences, vol. 22, no. 1, pp.66-86, 2014.

[6] J.L. Marquez, M.G. Molina, J.M. Pacas, "Dynamic modeling, simulation and control design of an advanced microhydro power plant for distributed generation applications," International Journal of Hydrogen Energy, vol. 35, no. 11, pp. 5772-5777, 2010.

[7] I. Salhi, S. Doubabi, N. Essounbouli, A. Hamzaoui, "Application of multi-model control with fuzzy switching to a micro hydro-electrical power plant," Renewable Energy, vol. 35, no. 9, pp. 2071-2079, 2010.

[8] M. Hanmandlu, H. Goyal, "Proposing a new advanced control technique for micro hydro power plants," International Journal of Electrical Power \& Energy Systems, vol. 20, no. 4,pp. 272-282, 2008.

[9] S. Doolla, T.S. Bhatti, R.C. Bansal, "Load frequency control of an isolated small hydro power plant using multi-pipe scheme," Electric Power Components and Systems, vol. 39, no. 1, pp. 46-63, 2011.

[10] B. Singh, V. Rajagopal, "Neural-Network-Based integrated electronic load controller for isolated asynchronous generators in small hydro generation," IEEE Transactions on Industrial Electronics, vol. 58, no. 9, pp. 4264-4274, 2011.

[11] L. Belhadji, S. Bacha, I. Munteanu, A. Rumeau, D. Roye, "Adaptive MPPT applied to variable-speed micro hydro power plant," IEEE Transactions on Energy Conversion, vol. 28, no. 1, pp. 34-43, 2013.

[12] E. Özbay, M.T. Gençglu, "Load frequency control for small hydro power plants using adaptive fuzzy controller," in Proceedings of IEEE
2010 International Conference on Systems, Man and Cybernetics, (Istanbul, Turkey), pp. 4217-4223, Oct. 2010.

[13] H. Mohamad, H. Mokhlis, A. Abu Bakar, H.W. Ping, "A review on islanding operation and control for distribution network connected with small hydro power plant," Renewable and Sustainable Energy Reviews, vol. 15, no. 8, pp. 3952-3962, 2011.

[14] V.I. Utkin, Sliding Modes in Control and Optimization (2nd ed). Berlin, Germany: Springer-Verlag, 1992.

[15] M. Dybkowski, T. Orlowska-Kowalska, G. Tarchala, "Sensorless traction drive system with sliding mode and MRAS(CC) estimators using direct torque control," Automatika, vol. 54, no. 3, pp. 329-336, 2013.

[16] D. Liu, M.G. Li, “Adaptive wavelet neural network backstepping sliding mode tracking control for PMSM drive system," Automatika, vol. 55, no. 4, pp. 405-415, 2014.

[17] L. Cheng, Z. Hou, M. Tan, "A mean square consensus protocol for linear multi-agent systems with communication noises and fixed topologies," IEEE Transactions on Automatic Control, vol. 59, no. 1, pp. 261-267, 2014.

[18] L. Cheng, Y.Wang, Z. Hou, M. Tan, Z. Cao, "Sampled-data based average consensus of second-order integral multiagent systems: switching topologies and communication noises," Automatica, vol. 49, no. 5, pp. 1458-1464, 2013.

[19] A. Zargari, R. Hooshmand, M. Ataei, "A new control system design for a small hydro-power plant based on particle swarm optimization-fuzzy sliding mode controller with Kalman estimator," Transactions of the Institute of Measurement and Control, vol.34, no. 4, pp. 388-400, 2012.

[20] D. Qian, J. Yi, X. Liu, "Design of reduced order sliding mode governor for hydro-turbines," In Proceedings of 2011 American Control Conference, (San Francisco, CA), pp.5073-5078, June 29 -July 12011.

[21] X. Ding, A. Sinha, "Sliding mode/H1 control of a hydropower plant," In Proceedings of 2011 American Control Conference, (San Francisco, CA), pp. 5201-5206, June 29 - July 12011.

[22] K. Vrdoljak, N. Peric, I. Petrovic, "Applying optimal sliding mode based load-frequency control in power systems with controllable hydro power plants," Automatika, vol. 51, no. 1, pp. 3-18, 2010.

[23] K. Vrdoljak, N. Peric, I. Petrovic, "Sliding mode based load-frequency control in power systems," Electric Power Systems Research, vol. 80, no. 5, pp. 514-527, 2010.

[24] R. Hooshmand, M. Ataei, A. Zargari, "A new fuzzy sliding mode controller for load frequency control of large hydropower plant using particle swarm optimization algorithm and Kalman estimator," European Transactions on Electrical Power, vol. 22, no. 6, pp. 812$830,2012$.

[25] M.R. Rani, H. Selamat, H. Zamzuri and Z. Ibrahim, Multiobjective optimization for PID controller tuning using the global ranking genetic algorithm, Int J Innov Comput, Inf Control 8(1A) (2012), 269-284.

[26] S. Dormido, E. Pisoni and A. Visioli, Interactive tools for designing fractional-order PID controllers, Int J Innov Comput, Inf Control 8(7A) (2012), 4579-4590.

[27] V. Donde, M. A. Pai, and I. A. Hiskens, "Simulation and Optimization in an AGC System after Deregulation," IEEE Transactions on Power Systems, vol. 16, pp. 481-489, Aug. 2001.

[28] M. Aldeen, and R. Sharma, "Robust Detection of Faults in Frequency Control Loops," IEEE Transactions on Power Systems, vol. 22, no. 1, pp. 413-422, Feb. 2007.

[29] Y. Moon, H. Ryu, B. Choi, and H. Kook, "Improvement of System Damping by Using the Differential Feedback in the Load Frequency Control," IEEE Power Engineering Society 1999 Winter Meeting, vol. 1, pp. 683-688, Feb. 1999.

[30] Y. Moon, H. Ryu, J. Lee, and S. Kim, "Power System Load Frequency Control Using Noise-Tolerable PID Feedback," IEEE International Symposium on Industrial Electronics, vol. 3, pp. 1714-1718, Jun. 2001.

[31] Y. Moon, H. Ryu, B. Choi, and B. Cho, "Modified PID LoadFrequency Control with the Consideration of Valve Position Limits," IEEE Power Engineering Society 1999 Winter Meeting, vol. 1, pp. 701-706, Feb. 1999.

[32] D. Rerkpreedapong, and A. Feliachi, "PI Gain Scheduler for Load Frequency Control Using Spline Techniques," The 35th Southeastern Symposium on System Theory, pp. 259-263, Mar. 2003.

[33] M. Rahi, and A. Feliachi, "Hळ Robust Decentralized Controller for Nonlinear Power Systems," The 30th Southeastern Symposium of System Theory, pp. 268-270, Mar. 1998.

[34] I. Ngamroo, Y. Mitani, and K. Tsuji, "Robust Load Frequency Control by Solid-State Phase Shifter Based on Hळ Control Design," IEEE Power Engineering Society 1999 Winter Meeting, vol. 1, pp. 725-730, Feb. 1999.

[35] A. Bensenouci, and A. Ghany, "Mixed $\mathrm{H} \infty / \mathrm{H} 2$ with Pole-Placement Design of Robust LMI-Based Output Feedback Controllers for Multi- 
Area Load Frequency Control," Proceedings of The International Conference on Computer as a Tool, pp. 1561-1566, Sep. 2007.

[36] D. Rerkpreedapong, and A. Feliachi, "Decentralized Ho Load Frequency Control Using LMI Control Toolbox," The 2003 International Symposium on Circuits and Systems, vol. 3, no. 25-28, pp. 411-414, May 2003.

[37] A. Paradkar, A. Davari, and A. Feliachi, "Disturbance Accommodation Control versus Conventional Control, in LFC of a Two Area Distribution System in a Deregulated Environment," The 35th Southeastern Symposium on System Theory, pp. 98-102, Mar. 2003.

[38] Y. Moon, H. Ryu, B. Kim, and K. Song, "Optimal Tracking Approach to Load Frequency Control in Power Systems," IEEE Power Engineering Society 2000 Winter Meeting, vol. 2, pp. 1371-1376, Jan. 2000.

[39] L. Kong, and L. Xiao, "A New Model Predictive Control SchemeBased Load- Frequency Control," Proceedings of IEEE International Conference on Control and Automation, pp. 2514-2518, Jun. 2007.

[40] B. Bakken, and O. Grande, "Automatic Generation Control in a Deregulated Power System," IEEE Transactions on Power Systems, vol. 13, no. 4, pp. 1401-1406, Nov. 1998.

[41] Ibraheem, P. Kumar, and D. Kothari, "Recent Philosophies of Automatic Generation Control Strategies in Power Systems," IEEE Transactions on Power Systems, vol. 20, no. 1, pp. 346-357, Feb. 2005.

[42] T. Hiyama, S. Koga, and Y. Yoshimuta, "Fuzzy Logic Based MultiFunctional Load Frequency Control," IEEE Power Engineering Society 2000 Winter Meeting, vol. 2, pp. 921-926, Jan. 2000.

[43] K. Yukita, Y. Goto, K. Mizuno, T. Miyafuji, K. Ichiyanagi, and Y. Mizutani, "Study of Load Frequency Control using Fuzzy Theory by Combined Cycle Power Plant," IEEE Power Engineering Society 2000 Winter Meeting, vol. 1, pp. 422-427, Jan. 2000.

[44] H. Mohamed, L. Hassan, M. Moghavvemi, and S. Yang, "Load Frequency Controller Design for Iraqi National Super Grid System Using Fuzzy Logic Controller," SICE Annual Conference, pp. 227 232, Aug. 2008.

[45] D. Rerkpreedapong, A. Hasanovic, and A. Feliachi, "Robust Load Frequency Control Using Genetic Algorithms and Linear Matrix Inequalities," IEEE Transactions on Power Systems, vol. 18, no. 2, pp. 855-861, May 2003.

[46] R.K. Sahu, S. Panda, G.T.C. Sekhar, A novel hybrid PSO-PS optimized fuzzy PI controller for AGC in multi area interconnected power systems, Int. J. Elect. Power Energy Syst. 64 (2015) 880-893.

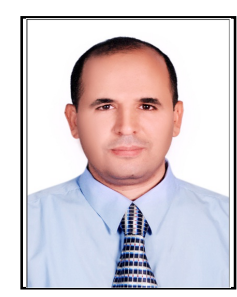

Adel Elgammal is currently an Associate Professor at the University of Trinidad and Tobago UTT, Department of Energy Systems. He received his B.Sc. Degree in Electrical Power Engineering from Helwan University-EGYPT in 1996. He completed his M.Sc. Degree in Electric Drives and Machines Engineering in 2002 and Ph.D. Degree in Jan-2007 from the Faculty of Engineering (Helwan University-EGYPT). In May 2008, Dr. Elgammal joined the University of Trinidad and Tobago (UTT) as an Assistant Professor and then he was promoted to Associate Professor in May 2010 at the Energy Department, UTT. Dr. Elgammal authored and co-authored over 47 Scholarly Technical Journals, and over 77 Refereed Conference Publications and three Engineering Book Chapters. In 2010, Dr. Elgammal has been elevated to senior member of Institute of Electrical and Electronics Engineers (IEEE), the world's largest professional association dedicated to advancing technological innovation and excellence for the benefit of humanity. His current Research areas include Power Systems and Electro-Technology, Motor Drives, FACTS Technology, Renewable/Alternate Energy Systems, Harmonics and Power Quality, Application of Intelligent Systems (Particle Swarm Optimization PSO, Fuzzy Logic, Neutral Networks, and Genetic Algorithms) to Power Systems, Renewable / Green Energy Systems and Electric Drives, Application of Power Electronics to Power Systems, Computer-Based Controllers. Dr. Elgammal has gained industrial and academic experience as well as participated in several technical consultations and professional experience.

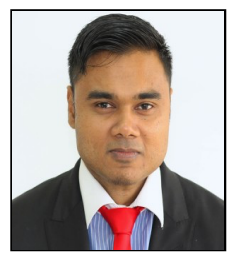

Curtis Boodoo currently holds the position of Assistant Professor in the Utilities Engineering Unit at the University of Trinidad and Tobago (UTT). He has been a faculty member at UTT since 2004 and Program Coordinator for the Electrical / Electronics Engineering Diploma program at the John Donaldson campus since 2008. He has contributed towards the development of the Sustainable Energy Implementation Plan 2021/2030 for Trinidad and Tobago, The National Energy Policy and the National Integrated Solid Waste Management Strategy. He has also represented UTT at the Renewable Energy and Energy Efficiency subcommittee of the Economic Development Board of Trinidad and Tobago. He currently holds the position of Expert in the Systems Evaluations Group (SEG4) - Low Voltage Direct Current Applications, International Electrotechnical Commission (IEC) and was a member of the Specifications Committee for Electrical Appliances at the Trinidad and Tobago Bureau of Standards (TTBS). 